\title{
Formação em ciências da saúde: diálogos em saúde coletiva ea educação para a cidadania
}

\author{
H ealth sciences education: \\ dialogues in public health and the education for the citizenship
}

Denise Alves Guimarães ${ }^{1}$

Eduardo Sergio da Silva ${ }^{1}$

\footnotetext{
${ }^{1}$ Universidade Federal de São João Del-Rei. Av.

Abstract In the last decades there have been discussions concerning the educational process of health professionals in Brazil. The discussed subjects are based on the verification of precarious aspects concerning a kind of formation that should befocused on attending the demands of the population, on the principles of SUS and an extended understanding of healthcare. We intended to think about alternatives in relation to the graduation in health sciences and in analyzing the way education in health is registered in the context of higher education.

Key words Formation, University graduation, $\mathrm{H}$ ealth sciences
Resumo Nas últimas décadas, tem havido discussões acerca do processo de formação de profissionais da saúde no Brasil. Os temas tratados se baseiam na constatação de pontos precários em relação a uma formação que deveria se voltar ao atendimento das demandas da população, para os princípios do SU S e uma compreensão ampliada da saúde. Buscamos pensar alternativas em relação à graduação nas ciências da saúde e analisar de que maneira esta formação se inscreve no contexto do ensino superior.

Palavras-chave Formação, Graduação universitária, Ciências da saúde 
Introdução

A velocidade dos avanços da ciência e tecnologia nas últimas décadas é considerada a maior que a humanidade pode presenciar. No entanto, ainda não foi possível aos homens estabelecerem uma correlação direta entre desenvolvimento científico e tecnológico e o nível de desenvolvimento humano e social. Se entre os avanços tecnológicos e científicos e 0 acesso aos mesmos por parte dosindivíduos e col etividades existe uma distância, esta é uma questão que merece atenção não só em relação às repercussões que traz para as práticas em saúde, como também em relação à formação em saúde.

Em relação à velocidade dos avanços mencionados e o descompasso de sua aquisição, assimilação, acesso e avaliação, as dificuldades se referem não só aos conteúdos e métodos de aprendizagem, como também à maneira de avaliar criticamenteo conhecimento esuas formas de utilização. A maneira como lidamos com os novos conhecimentos na contemporaneidade exigeque busquemos desenvolver marcos conceituais e abordagen s mais críticas que nos permitam compreender um mundo derápidas mudanças egrandes contradições, bem como pela necessidade de nos situarmos em um cenário em que os limites até então estabelecidos para cada uma das áreas deconhecimento passam por profundas revisões.

Tratando-se da necessidade de revisão do modelo deformação universitária em nosso país, o decreto $n^{0} 6.096^{1}$ parte de um diagnóstico dos principais problemas que afetam as universidades públicas e propõe uma reorganização de sua estrutura, buscando a criação de melhores condições para 0 acesso ao ensino superior, bem como as condições para a conclusão desses estudos. 0 decreto institui o programa de apoio a planos de Reestruturação e Expansão das Universidades Federais (REUNI) com diretrizes que buscam a redução das taxas de evasão e ocupação de vagas ociosas, além do aumento de vagas de ingresso; ampliação da mobilidade estudantil; revisão da estrutura acadêmica; diversificação das modalidades de graduação, preferencialmente não voltadas à profissionalização precoce e especializada; ampliação da política de inclusão social e articulação da graduação com a pós-graduação e da educação superior com a educação básica.

Diante da importância e da complexidadedas discussões sobre a reformulação da formação universitária no Brasil, o presenteartigo tem como objetivo estabelecer uma discussão conceitual so- bre o que compreendemos por formação e sua relação com o ensino superior no Brasil com vistas à discussão da formação em saúde, especificamente com o enfoque da Saúde Coletiva.

\section{A formação superior no Brasil: o queéisso?}

A educação superior no Brasil hojeétratada pela Constituição Federal de $1988^{2}$ e regulamentada pela Lei de Diretrizes e Bases da Educação (LDB) e constitui-se como o segundo nível estrutural da educação escolar. De acordo com Carneiro ${ }^{3}$, a LDB postula que a universidade moderna desempenha quatro funções essenciais: formar profissionais; oferecer educação em nível avançado; realizar estudos, pesquisas e investigação científica voltada para o desenvolvimento e, por fim, funcionar como instituição social.

Sobre a configuração da educação superior no Brasil, o autor destaca o crescimento da rede privada e a estagnação da rede pública como pontos que colocam a necessidade de uma reavaliação do sistema de ensino superior, uma vez que, dentre os países da América Latina, o Brasil apresenta os mais baixos índices de acesso à educação superior. Para a faixa etária entre 18 e 24 anos no Brasil, apenas $12 \%$ acessam o ensino superior enquanto na Argentina esseíndice chega a $40 \%$, na Venezuela, $26 \%$, na Bolívia, $20,6 \%$ e no Chile, $20 \%$. Além disso, apesar da ampliação do acesso ao ensino superior no Brasil, observado nas últimas décadas, as taxas de escolarização $(6,7 \%)$ ainda são baixas se comparadas com a Argentina (22,4\%), Uruguai $(11,3 \%)$ e com os países membros da Organização para a Cooperação e Desenvolvimento Econômico (OCDE), cuja média éde $23,2 \%$.

Calderón ${ }^{4}$ aponta que, a partir do regime militar, especificamente com a reforma universitária de 1968 (Lei n 5.540), importantes mudanças são introduzidas e ocorre, no plano legal, um fortalecimento das universidades na medida em quea lei decreta queo ensino superior deveria ser ministrado prioritariamente por universidades e apenas em caráter excepcional em faculdades. Além disso, defineum modelo único deuniversidade pública e gratuita que deveria se pautar no princípio da indissociabilidadeentreensino, pesquisa e extensão. N o entanto, o que se observou na prática foi um desrespeito ao plano legal e uma expansão do ensino privado por meio das faculdades. 0 autor destaca que. desde a década de sessenta, a pressão social por vagas no ensino superior era bastante grande e a resposta do go- 
verno militar a esse problema foi uma avalanche de autorizações para abertura de novas escolas e também para que as escolas já existentes aumentassem suas vagas sem atender a grandes exigências burocráticas.

Calderón ${ }^{4}$ ressalta que os demais países da América Latina resolveram o problema da demanda de democratização do ensino superior massificando as universidades públicas. No Brasil, ao contrário, o regime militar optou pelo investimento financeiro na formação de uma universidade pública de el ite voltada para a pesquisa equeacarretou a manutenção do número restrito de alunos. Paralelamente, optou pelo incentivo da criação de um sistema de ensino superior de massa vinculado à iniciativa privada, constituindo amplo campo de investimento dos empresários da educação, que optaram em investir na criação de estabelecimentos isolados de pequeno porte. As universidades mercantis criadas a partir deste período apresentam-se, em sua maioria, com um caráter de empresa privada capitalista com claro objetivo de obtenção de lucro eacumulação de capital, além de se comprometerem quase exclusivamente com a transmissão de conhecimentos em detrimento de atividades de pesquisa e extensão.

Sobral ${ }^{5}$ discute que a abordagem contemporânea dada à educação na sociedade brasileira se estrutura sob dois aspectos: a educação como promotora decompetitividadeea educação como promotora de cidadania social. Para a autora, a nova LDB reflete estas duas dimensões e outro ponto de relevância na pauta de discussões sobre o ensino superior no Brasil seria a saída do modelo único, possibilitando à universidade o oferecimento de formação científica, profissional, tecnológica e formação de professores.

Fazendo uma revisão da educação na sociedade brasileira, Sobral ${ }^{5}$ aponta que, no período que vai dos anos cinquenta até $o$ início da década de sessenta, a educação era considerada um instrumento demobilidadesocial. A educação apresentava, além das funções de socialização e formação, a função de dar "status" aos indivíduos. Esta perspectiva se insere em um contexto de reestruturação da sociedade, abalada pela $2^{\underline{a}}$ Guerra Mundial e, no Brasil, a educação se colocava para fortalecer ideias de democracia com o objetivo de diminuir o poder das oligarquias, fortificar a burguesia nascente, dar uma certa participação eleitoral às massas e estimular a industrialização.

No período que vai de meados da década de sessenta aos anos setenta, a educação aparece na sociedade brasileira, de acordo com a autora, como possibilidade de evidenciar os seus aspectos econômicos, ou seja, as possibilidades de rendimentos oferecidos pela educação. A autora nota que, naquele período, já aparece a discussão sobre a concepção da educação como mercadoria, uma vez que esta aparece associada à melhoria de renda através de uma maior qualificação para o mercado detrabal ho. N esta fase, o contexto mundial se caracterizava pela consolidação do capitalismo monopolista, o conceito de "capital humano" passava a interferir no desenvolvimento econômico e havia a crescente interven ção dos Estados na economia. No Brasil, vivíamos o governo autoritário, a ideologia desenvolvimentista, intervenção do Estado na economia, industrialização progressiva e internacionalização da estrutura produtiva. Com o "milagre econômico brasileiro" (a partir de 1968), a política educacional preocupa-seprincipalmentecom arentabilidadedos investimentos educacionais e os principais frutos dessa política são a reforma universitária de 1968 e a Lei de Profissionalização do Ensino M édio de 1971. O objetivo era profissionalizar equalificar a mão de obra para o desenvolvimento econômico do país. A reforma universitária de 1968 partiria do princípio de que a universidade mostrava-se inadequada para o processo de desenvolvimento e modernização e a função social da mesma nesse momento era qualificar recursos humanos e produzir conhecimento científico etecnológico para permitir a expansão industrial brasileira.

No final da década de setenta e década de oitenta, com a redemocratização, Sobral ${ }^{5}$ aponta que a educação passa a ser considerada em seu aspecto político como possibilidade de construção da cidadania. 0 contexto mundial assiste ao auge do Estado de bem-estar-social e ênfase na democratização. 0 papel da universidadeno Brasil se vincula à construção da cidadania a partir da ampliação de seu acesso, autonomia de gestão e busca a contribuir para a autonomia do país através de desenvolvimento de ciência e tecnologia. 0 novo contexto de desenvolvimento do Brasil aparece como sinônimo de autonomia nacional através da geração de conhecimento científico e tecnológico, buscando a superação da dependência em relação aos países centrais. N este momento, a função social da educação seria trazer ao indivíduo sua cidadania através do ensino público egratuito e também pela participação do indivíduo nas esferas do poder.

$N$ a década de noventa, a educação é considerada pela autora sobretudo como promotora de competitividade, dando ao indivíduo a condição de empregabilidade etrazendo para a sociedadea 
modernidade associada ao desenvolvimento sustentável. 0 contexto mundial écaracterizado pela globalização, menor intervenção do Estado na economia, maior competição entre os países, competitividade aumentada através da qualificação/formação derecursos humanoseo tripé"educação + ciência + tecnologia" aparece como caminho para o desenvolvimento. No Brasil, a política educacional apresenta ideias de educação para competitividadeetambém ideias deuma concepção social da educação (acesso à educação como possibilidade de diminuir desigual dades sociais).

Sobre a expansão do ensino superior brasileiro nas últimas três décadas, $M$ artins $^{6}$ destaca que, nesse processo de transformação, forma-se um campo acadêmico extremamente complexo, marcado por diferentes posições ocupadas pelas instituições, diferenças do corpo docente (titulação), diferença na capacidade científica, formatos organizacionais distintos, diferenças em relação ao prestígio, reconhecimento social esimbólico das instituições de ensino superior (IES).

Para 0 autor, há uma desconsideração ao aspecto legislativo, uma vez que hoje existem 973 IES, sendo que as universidades compõem $16 \%$ do conjunto e o restante é constituído por estabelecimentos isolados (faculdades). Das IES no país, 59\% estão concentradas na Região Sudeste e observa-se que $78 \%$ são estabelecimentos privados, enquanto $22 \%$ são do setor público. Além disso, o crescimento das IES privadas aumentou em $280 \%$. Observa-se também que as universidades públicas destacam-se no campo acadêmico nacional (bons resultados no Exame Nacional de Cursos eelevados conceitos nas avaliações da (APES). 0 autor destaca ainda que a maioria das federais surgiu na década de sessenta (final) e estão organizadas em uma rede nacional (Rede Unida), sendo que parte substancial da capacidade de pesquisa instalada no país encontra-se nessa rede. Além disso, o autor ressalta que as crises sucessivas nas universidades públicas apontam o esgotamento do modelo único queas rege.

$M$ artins ${ }^{6}$ também avalia que seria mais vantajoso estimular a pluralidade de modelos institucionais ao invés de insistir no modelo único. Outro ponto importantíssimo destacado por ele diz respeito ao fato de que, apesar do crescimento do ensino superior no Brasil, apenas 7,6\% da população entre 20 e 24 anos deidadetêm acesso a este nível de ensino. Há também um descompasso entre a expansão de matrículas eo número dealunos que concluem o curso devido ao fenômeno da evasão (fenômeno percebido também no Censo da Educação Superior de 20047).
Ribeiro ${ }^{8}$ desenvolve um enfoque crítico sobre a experiênciauniversitária latino-americana, apontando seus descontentamentos em relação à convivência da universidade com as forças responsáveis pelo atraso da América Latina, ao desempenho cultural ecientífico medíocres das mesmas e a sua irresponsabilidade frente aos problemas dos povos que a mantém. A pesar dessa constatação, o autor se al ega otimista por acreditar que é possível erradicar a conivência, superar a mediocridade e vencer a alienação que ele denuncia. As mudanças nas quais ele aposta se vinculam ao que ele chama de civilização solidária.

Casanova ${ }^{9}$, que também compartilha dos mesmos princípios, propõe pensarmos em uma "revolução pedagógica", identificando, de início, o que ele define como "preconceitos sobre a educação superior que a mantém no ponto em que está". Para ele, os sete preconceitos seriam: a educação superior deve ser para uma elite e não para as massas; a educação superior diminuiu a qualidade conforme é transmitida a um número maior de pessoas; somente uma proporção mínima de pessoas está apta para a educação superior $(0,01$ ou $1 \%)$; para a educação superior, devemse selecionar os mais aptos; não se deve possibilitar educação superior para além das possibilidades de emprego; o Estado já está gastando demais em educação superior e, por fim, não sedevequerer que todos sejam profissionais, pois seria horrível um mundo em que não houvesse operários.

Diante destes preconceitos, 0 autor vai abordar a ideia de revolução pedagógica, reafirmando a necessidade de criar uma universidade que antecipe a sociedade solidária. No entanto, ele alerta para o fato de que as reformas necessárias neste sentido só serão passíveis na medida em que se mudem radicalmente os conteúdos ensinados e sejam erradicados os componentes que representam o velho modelo. Em relação aos conteúdos, a "revolução pedagógica" deve propor conteúdos que não estejam exclusivamente vinculados aos interesses e modos de vida das elites eque possa criar novas formas de articulação das comunidades, elevando o padrão de vida das populações. Além disso, os conteúdos abordados devem preparar os graduados para assistir às grandes massas de população.

Conforme 0 autor, seria necessário direcionar a universidade para os interesses das massas e rever conteúdos de ensino, criando uma nova mentalidade que exigiria de alunos e professores disposição para que os projetos, avaliações e correções fossem decididos por todos os participantes através do debate aberto e livre. 
Assim, Casanova ${ }^{9}$ evidencia que as formas de aprendizagem envolvem a assimilação de lições dadas por professores; participação de debates; leitura de livros e outros materiais didáticos; investigação de temas e problemas; observação direta da realidade; interação entre professores e estudantes; aplicação de conhecimentos na solução de problemas concretos e através da participação na vida da comunidade a que pertence.

Evidenciada a complexidade do ensino superior no Brasil, gostaríamos de focar a discussão nas contribuições de Sobral ${ }^{5}$, ao apontar a existência de duas dimensões na educação brasileira ("educação para a cidadania" e "educação para o mercado") e nas contribuições de Ribeiro $0^{8}$ e Casanova ${ }^{9}$, ao mostrarem a ligação entre a universidade e o processo de formação do homem, compreendido aqui de forma abrangente e considerando a importância de valores como solidariedade, atendimento às demandas da população, inclusão social, democracia e dimensão política do processo de formação universitária.

\section{O desafio da formação na universidade}

Atéagora, o paradigma dominantena ciência, inscrito no modo capitalista de produção, tem nos levado à contínua divisão do conhecimento em disciplinas e destas em subdisciplinas. À medida que esta tendência foi se aprofundando, o conhe cimento setornou cada vez mais parcelado eespe cializado, abrangendo aspectos cada vez mais limitados da realidade. Examinando o modelo hegemônico desefazer ciência e as repercussões para os processos de formação e atuação, nos reportamosa Santos ${ }^{10}$, que chama a atenção para a excessiva parcelização edisciplinarização do saber científico de hoje, que faz do cientista um ignorante especializado, o que acarreta efeitos negativos.

Para 0 autor, desde seu surgimento, a universidade oscila entre duas exigências antagônicas. De um lado, as exigências que impeliram a organizar o conhecimento de forma parcelada e compartimentalizada, distinguindo disciplinas eespe cialidades. Por outro lado, as exigências de reunir as especialidades, disciplinas e áreas do conhecimento num espaço institucional comum (departamentos, faculdades, escolas, além das próprias universidades), buscando afinidades eunificação. Uma das consequências dessa dinâmica foi o surgimento do conflito até hoje ainda não resolvido entre o "generalista" (que se esforça por unificar e alargar o conhecimento) e o "especialista" (que se esforça por aprofundá-lo)"11.
$N$ a segunda metade do século $X X$, a necessidade de resgatar a integridade do conhecimento levou a novas abordagens, que consistem na articulação de várias disciplinas para se examinar determinado problema, tomando-se a especificidade de cada caso. Tais abordagens se inscrevem em termos de relações possíveis de serem estabeleci das entre disciplinas, buscando os pontos de convergência e divergência e as novas formas de se abordar a realidade, assumindo diferentes aspectos.

De acordo com Domingues ${ }^{11}$, se iniciam na França, em meados do século XX, as discussões sobreinterdisciplinaridade, pluridisciplinaridade emultidisciplinaridade. Na sequência, aparecem os termos "transdisciplinar" e "transdisciplinaridade", trazendo a ideia do "trans" como um ideal do conhecimento a ser perseguido no futuro.

A ideia de transdisciplinaridade aqui presente refere-se a toda busca para superar a compartimentalização do saber. Superação não no sentido de negação da especialidade e do saber próprio de cada ciência, mas de comunicação, busca de convergência e elaboração de conceitos emétodos compartilhados. A transdisciplinaridade que se pretende vai além da multidisciplinaridade: múltipla em sua origem, ela busca a fluidez das fronteiras sem, contudo, se tornar híbrida ou disforme. Trata-se, pois, de explicitar o rigor e, ao mesmo tempo, a amplitude do prefixo "trans", que dá um tom todo especial ao domínio disciplinar: professores/pesquisadores são convidados aqui a atuarem "entre", "através" e "além" das disciplinas, gerando, assim, as condições de possibilidades de um novo ethos da práxis intelectual-científica.

Partindo do princípio de que os modelos de ciência, formação e atuação profissionais contidos nas atuais concepções de formação universitária encontram sérias limitações em relação aos problemas que se apresentam na cena contemporânea, não poderíamos deixar de trazer um aprofundamento em relação à discussão acerca da nossa compreensão atual sobreformação. Assim, não pretendemos aqui resumir a formação aos processos de aquisição, transmissão e difusão de conhecimentos que se dão nos ambientes acadêmicos, ou seja, não pretendemos igualar formação e escolarização. N ossa opção em abordar os processos de formação passa necessariamente pelas ideias de Horkheimer e Adorno ${ }^{12}$ sobre a formação do homem no capitalismo tardio, que acabam por se revelar, de acordo com Adorno ${ }^{13}$, em uma pseudoformação, ou seja, a formação cultural reduzida à formação para o consumo. 
Os autores vão dizer que a crise da educação ou crise pedagógica deve ser compreendida em seu aspecto mais amplo enquanto crise da formação cultural. 0 colapso da formação cultural e, portanto, a complexidade da pseudoformação está em compreender que ela faz parte de um conjunto de fatores sociais que não devem ser vistos isoladamente e dissociados da formação cultural como um todo. Não se pode pensar na formação cultural e, portanto, na formação do indivíduo, isolando-a das condições concretas de existência e, nesta medida, a formação cultural do período em que vivemos é, para os autores, formação que renuncia às formas diferenciadas de socialização para apegar-se ao consumo.

0 sistema produtivo interessa-se pelos homens exclusivamente enquanto consumidores e trabal hadores e, nessa medida, o próprio sistema produtivo garante que os homens estarão restritos a estas duas categorias através da pseudoformação. Assim, percebemos que a pseudoformação passa a ser a forma dominante da consciência atual, na medida em que todo o processo de formação cultural é reduzido à conquista de profissões bem-sucedidas e que sustentem a ilusão de garantir o nosso acesso a diferentes faixas de consumo. Assim como é um reducionismo igualar termos como formação, educação e escolarização, também é um reducionismo igualar educação e formação à formação para o trabalho.

Nessa medida, podemos compreender porque hoje a educação se apresenta com alto grau de superficialidade e utilitarismo, servindo a um objetivo bem direcionado quenão dá espaço para a incorporação de valores, crítica e análise sobre os mesmos, ou seja, se coloca como meio de aumentar as vantagens decada indivíduo em situação de disputa pelo mercado de trabalho. 0 que assistimos hoje em larga escala é a reprodução da cultura das massas, a cultura do consumo de mercadorias e da disputa entre competidores. Assim, a educação incorpora conhecimentos que são convertidos em mercadorias para aumentar o valor individual (valor de mercado), ao invés de se vincular à construção de conhecimentos para a coletividade, solidariedade e autonomia.

Se, conforme disse Adorno, a formação é a apropriação subjetiva da cultura, então a pseudoformação é a apropriação subjetiva dos princípios da sociedade de consumo, ou seja, a apropriação de bens culturais. A pseudoformação nos impeleà barbáriena medida em que se desvincula dos cuidados que os homens deveriam ter no trato com os outros homens, no polimento nas relações. Quando pensamos nas relações que se estabelecem entre os homenssob a égide dacompetição e da estratégia (claramente entendida como guerra), compreendemos a frieza no trato que caracteriza a relações entre rivais e entre inimigos. Além disso, observando especificamente os problemas que hoje afetam a área da saúde em termos das relações entre profissionais de saúde e usuários do SUS, nos damos conta da frieza que tomou conta das relações entre as pessoas. Prova disso encontra-se no programa de nome "Humaniza SUS", que tenta resgatar ou construir uma dimensão mais humana das relações entre as pessoas.

Nessa medida, percebemos o quanto a formação para o trabalho enquanto formação para a competição e busca exclusiva de sobrevivência é regressiva, já que coloca o homem isolado e impedido de estabelecer relações cooperativas ou solidárias com outros homens.

$N$ ão se pretendedizer com tais exposições que não haja a possi bilidade de formação de qualidade. 0 que se pretende evidenciar éque a pseudoformação épreponderante, está pautada na adaptação e no fim em si mesma eque incorpora elementos da formação e converte-os em bens culturais a serem consumidos. Cabe ressaltar que a pseudoformação torna amplamente disponíveis os bens culturais emascara a exclusão, dificultando as possibilidades de identificarmos em que medida temos acesso à formação e em que medida consumimos os bens culturais. N essa medida, faz-se necessária uma constante avaliação crítica acerca de conteúdos, métodos e val ores subjacentes a diferentes formas e processos de transmissão de conhecimento para sabermosse, por exemplo, utilizamos termos como humanização, respeito às diferenças, ética, cidadania e solidariedade porque hoje é moda sua utilização ou porque efetivamente apontam um caminho diferente do que aquele que estamos trilhando hoje.

Por fim, se a pseudoformação é a formação para a sociedade do consumo, temos que nos lembrar que consumir é destruir e esse ponto nos parece de extrema importância para pensarmos em como a sociedade passa por um momento de grande potencial destrutivo, que reduz pessoas, coisas, ideias, pensamentos, conhecimentos eformas de vida a objetos de consumo. Além do mais, qual tem sido o papel desempenhado pelas universidades diante destas questões? Como as diferentes instituições de ensino superior têm discutido essas duas dimensões do ensino: formação para a competitividade ou formação para a cidadania? A seguir, tentaremos refletir sobre alguns pontos que se referem especifi- 
camente à formação nas ciências da saúde que possam contribuir para a discussão do que foi abordado até o momento.

Repensando a formação

nas ciências da saúde

Nestetrabal ho, são considerados prioritariamente como cursos de formação em ciências da saúde al guns dos cursos circunscritos aos blocos de carreiras definidos pelo M inistério da Educação como pertencentes à área da saúde (ciências biológicas, enfermagem, farmácia, fisioterapia, fonoaudiologia, medicina, nutrição, odontologia e terapia ocupacional) e também alguns dos cursos que fazem a interface entre as áreas de ciências humanas e saúde (psicologia e ciências sociais). Tal critério de definição dos cursos que compõem a área de formação em discussão se justifica por representarem, no momento atual, a possibilidade maisimediata deincremento nas discussõese práticas que visam a uma mudança na formação e atuação profissional na área de saúde. N esse sentido, as mudanças na formação e atuação devem ser estruturadas com vistas a uma aproximação entre a atuação profissional ea atenção integral e humanizada à população brasileira ${ }^{14}$. Considerando 0 desafio de atender às exigências específicas de cada uma das áreas de conhecimento, mas também a necessidade imediata de atenção humanizada, faz-se necessário pensar na articulação entre os cursos específicos da saúde e os que fazem a interface saúde - ciências humanas.

A proposta de repensar a formação em ciências da saúde parte do princípio de que todo o movimento que coloca os processos de saúdeadoecimento como mercadorias deve ser rechaçado. A compreensão queo Estado brasileiro tem de saúde é como um direito e não como mercadoria e, sendo assim, a responsabilidade sobre a saúde deve ser entendida de forma coletiva enão como um bem de apropriação privada, dependente das diferentes condições econômicas que se colocam para sua compra evenda. Assim, tornam-senecessárias as ações de fortalecimento da Saúde Pública, especialmente considerando-se a complexidade de conceitos e ações contidos na ideia de Saúde Coletiva.

Para a discussão que nos propusemos realizar neste artigo, nossos esforços se voltam para a reflexão acerca da incorporação de uma perspectiva transdisciplinar nas ciências da saúde e de uma formação para a cidadania à medida que diversas áreas do conhecimento podem ter como ponto de convergência o enfoque na Saúde Coletiva, buscando um rompimento com a lógica de produção capitalista que incorpora os processos saúde-adoecimento ao rol das mercadorias.

Para percebermos mais claramente a abrangência de uma discussão que propõe uma mudança na formação de profissionais da área de saúde, faz-se necessário um exame de diferentes conceitos sobre saúde e seu processo de desenvolvimento para que possamos perceber quais os pontos em que os avanços teóricos devem apresentar-se concretamente em desdobramentos da formação e da prática.

O conceito desaúdefoi definido pela O rganização Mundial de Saúde no ano de 1946 como um estado de completo bem-estar físico, mental e social enão apenas a ausência de doenças, afirmando ainda que o gozo de melhor estado de saúde constitui um direito fundamental detodos os seres humanos, sejam quais forem suas raças, religiões, opiniões políticas, condições econômicas e sociais ${ }^{15}$.

Este conceito, querepresentou um avanço em termos de ampliação das dimensões que compõem a saúde, para além da simplificação deuma relação de oposição com a doença, suscita questionamentos importantes no momento.

A separação das dimensões física, mental e social traz a marca da prevalência do paradigma que vê o homem, e os conhecimentos desenvolvidos sobre ele, dividido, parcelado e sem integração. $\mathrm{N}$ a realidade, só existe homem que é ao mesmo tempo um sujeito complexo em seus aspectos somáticos, psíquicos e sociais, indissociavelmente.

Ao definir a saúde como uma situação de completo bem-estar, esse conceito nos coloca o problema da crença em um estado ideal possível de ser al cançado e que traz a ideia de estaticidade, como tão bem nos alertam Segree Ferraz ${ }^{16}$. Além disso, esse conceito se apoia na crença em um estado de permanência e completude de relações harmônicas do homem consigo mesmo, do homem com outros homens e do homem com o meio ambiente. I deias estas que contrariam o fato dequeo ser humano está continuamenteem processo de desenvolvimento de suas potencialidades e condições de vida, contrariam o tempo em que vivemos e anulam toda a abrangência das relações sociais contraditórias, inerentes ao nosso tempo.

Por fim, não se pode encarar saúde e doença como entidades opostas. Trata-se, na verdade, de uma complexa rede de relações que caracterizam o processo saúde-adoecimento como fenômenos da vida e que afirma, ao invés de negar, 
que morrer, adoecer, correr riscos e sofrer também fazem parte da existência ${ }^{17}$.

Vale destacar que a compreensão ampliada acerca dos determinantes da saúde e adoecimento para indivíduos e coletividades nos leva a dar atenção especial à complexidade de fenômenos que compõem a realidade, tais como a maneira como as coletividades estão organizadas nas cidades e no campo; as especificidades ambientais de cada região; o contato com ambientes poluídos; as condições e hábitos al imentares; as questões de exclusão social, a violência e a miséria; 0 grau de desenvolvimento social e econômico; as questões de infraestrutura (água, saneamento, luz, transporte, etc.); as condições de trabalho e moradia; o papel que as drogas e o álcool desempenham na vida dos indivíduos e das coletividades; as especificidades culturais de cada região e os valores e crenças de cada indivíduo ou grupo; as desigualdades de renda e condições de vida; a acessibilidade às diversas formas de informação e avanços tecnológicos, aos serviços de saúde, educação e lazer, bem como a maneira como os indivíduose as coletividades participam das questões sociopolíticas. N esta medida, qualquer proposta de formação e atuação em saúde, considerando este conceito de forma ampliada e multifacetada e que busque uma integralidade do conhecimento, passa obrigatoriamente pela análise de uma realidade hipercomplexa ${ }^{18,19}$.

Para compreendermos alguns determinantes históricos do caminho até um conceito ampliado de saúde, interessa-nos aqui explicitar, mesmo que de forma abreviada, como se desenvolveu a discussão da saúde no Brasil a partir dos questionamentos do modelo preventivista. Autores como Arouca ${ }^{20}$, Tambellini ${ }^{21}$ e CarvaIho ${ }^{22}$, dentre outros, nos mostram que o modelo preventivista no Brasil, presente até a década de setenta, se colocava a serviço do favorecimento deinteresses privatistas na saúde, ao mesmo tempo em que se mostrava incapaz de transformar a essência das práticas sanitárias. N esse cenário de crise social marcado pela alta prevalência de doenças vinculadas à pobreza ${ }^{23}$, emergiu a perspectiva da Saúde Coletiva, representando, segundo Arouca ${ }^{20}$, uma ruptura do pensamento preventivista, configurada na articulação da saúde pública com a medicina social.

A Saúde Coletiva apareceno conceito deTambellini ${ }^{21}$ como [...] um campo de práticas científicas, teóricas e empíricas, multi etransdisciplinares, e no plano da ação- interven ção, como um campo de práticas multifacetárias (sociais, políticas, econômicas, biotécnicas, educacionais), onde o cuida- do é considerado um núcleo estrutural consistente, sendo tais práticas orientadas pela necessidade coletiva sobre os condicionantes e o próprio processo saúdedoença. Ambos os campos são situados pela responsabilidade ética, social e política, que tem como sentido - valor, a saúde como bem comum. Trata-se de uma abordagem interdisciplinar, que abrange o indivíduo, os grupos, as comunidades e as dimensões institucionais e que articula diferentes disciplinas e perspectivas teórico-metodológicas dentro das ciências da saúde.

Assim, a atuação do profissional desaúdepode sedar em nível preventivo e/ou terapêutico, superando, paulatinamente, uma atuação puramente curativa para uma perspectiva de prevenção epromoção da saúde, na medida em que este profissional se perceba como um ator social em interlocução com os demais atores do tecido social.

Os desafios colocados pela real idade, as limitações dos model os tradicionais de atenção à saúde, a emergência de novas áreas de atuação para o profissional da saúde, a ampliação e diversificação da clientela atendida, as inovações nos procedimentos e técnicas e a integração em equipes multiprofissionais são eixos que levam à necessidade de revisitar os conceitos, a formação e as práticas em saúde.

Dentreas críticas quetêm sido feitas aos profissionais de saúde que se formam, a principal é em relação ao seu perfil profissional voltado para a atuação em instituições privadas e seu consequente despreparo para lidar com a SaúdePública. Tão evidente é a preocupação com a formação de recursos humanos em saúde que esta temática tem merecido a atenção de diversas iniciativas governamentais nacionais einternacionais de discussão, destacando-se o seminário internacional sobre políticas de recursos humanos de 200224. Assim, a formação profissional em saúde voltada para a imagem socialmente construída de "profissionais liberais bem-sucedidos" deve ser repensada, uma vez que nossa realidade impõe outras expectativas em relação à atuação dos profissionais de saúde.

Pensar o processo de formação universitária de profissionais de saúde passa necessariamente pelo que consideramos como compromissos de uma educação para a cidadania e que se expressam pelo atendimento aos princípios estabelecidos no SU $S^{25}$ eàs demandas da população e pela atuação profissional marcadamente distinta da tradicional atuação em saúde com um perfil de profissional liberal. Entende-se aqui a formação para a cidadania como um conjunto de práticas politicamente comprometidas, norteadas pela 
necessidade de novas respostas aos problemas dos homens em sua relação com outros homens, com as coletividades e com as questões ambientais. Trata-se de uma resposta mais efetiva em relação às expectativas sociais dirigidas aos profissionais que atuam em saúde e voltadas aos compromissos sociais que sua formação estabelece com os demais atores sociais.

Rever a formação universitária é pensar no desenvolvimento de competências específicas para a atuação profissional na área de saúde e também na capacidade de avaliar, criticar, interagir, integrar e reformular as práticas profissionais considerando a diversidade dos indivíduos ecoletividades. Para isso, busca-sedar ênfase aos preceitos éticos, técnicos, políticos e ambientais que revelem o respeito à diversidadeeao enfoque da Saúde Coletiva, compreendida como o campo no qual se inscrevem as múltiplas dimensões indissociáveis do ser humano, para além dos fenômenos biológicos e orgânicos, considerando sua inserção no contexto sócio-histórico e as relações que constrói a partir dessa inserção. A SaúdeColetivaéum espaço de convergência de ações e discursos das áreas de saúde e ciências humanas que se voltam para questões pertinentes ao tratamento, prevenção epromoção da saúde, seja em espaços públicos ou privados, formais ou informais, nas organizações de trabalho, instituições de educação, na família, nos movimentos sociais, em sistemas cooperativos e organizações do terceiro setor.

Trata-se de uma formação que busca compreender o processo saúde-adoecimento em sua ligação estreita com as questões ambientais, com as relações de poder historicamente construídas e que acabam por colocar os atores sociais (organizações, sujeitos e as coletividades) em uma relação de submissão aos profissionais de saúde. Refere-se também à busca de apropriação de conhecimentos e práticas em saúde e pela conquista deautonomia deindivíduose col etividadesem relação ao processo saúde-adoecimento eà qualidade de vida, além da construção de uma mentalidade de coparticipação entre o profissional desaúdee outros atores que demandam sua atenção eseus conhecimentos específicos.

\section{Consideraçõesfinais}

A partir das questões apresentadas ao longo deste texto, avaliamos queo mais prudente para este momento seria pensar nos desafios concretos que se colocam para 0 avanço de propostas que bus- quem fazer da formação universitária em saúde uma oportunidade de construir a formação para a cidadania.

Com base nas discussões apresentadas no início deste texto sobre o problema da expansão da rede privada de ensino no país, concordamos que tal ponto já se mostraria suficiente para a condução de uma reavaliação do sistema de ensino superior no Brasil. No entanto, acreditamos que a atual situação exige também medidas maisimediatas quepodem ser deflagradas a partir da discussão sobre o processo de avaliação do sistema educacional brasileiro, especificamenteno que tange às questões afetas ao ensino superior.

Apesar da expansão da rede privada, é imprescindível lembrarmos que tanto na Constituição Federal quanto na LDB está afirmada a liberdade de investimentos da iniciativa privada na educação. Além disso, não teria sentido pensarmos na necessidade de retomada da expansão de um ensino público voltado para os interesses col etivos, desconsiderando a existência das instituições formadoras de caráter privado e 0 número de profissionais por elas formados. Não se trata, portanto, de afirmar que o ensino voltado para 0 atendimento das necessidades da sociedade brasileira só poderia ocorrer através do ensino público, mas muito mais a necessidadede reafirmar efortalecer o papel do Estado brasileiro na definição de parâmetros de uma educação superior que garanta o desenvolvimento social, em quaisquer instituições onde possa ocorrer.

Ao mesmo tempo, está claramente expressa a responsabilidade da União em relação à avaliação da qualidade do ensino oferecido pelas IES privadas. Nesta medida, considerando que cabe à União assegurar o processo de avaliação do ensino superior no país com vistas à definição de prioridades eà melhoria da qualidade do ensino, consideramos prudente pensar na urgência de mudanças no sistema de avaliação. N ão obstante a impossibilidade de aprofundamento dessa discussão para o espaço deste texto, gostaríamos apenas de alertar sobrea necessidade de que o processo de avaliação comporte discussões bastante amplas sobre o que define qualidade de ensino. Seria no mínimo temerário centrar a discussão em conteúdos e programas ou estrutura física de IES, sem incorporar as diferenças das condições de trabalho para docentes de instituições públicas e privadas e as repercussões destas para o processo de formação. Neste ponto, chamamos a aten ção para al gumas das especificidades que envolvem as relações de trabalho no setor privado de educação e merecem ser analisa- 
das: regime de trabalho horista; falta de investimentos e incentivos em qualificação docente; pouca ou nenhuma oportunidade para desenvolvimento de atividades de pesquisa e extensão; fal ta de estabilidade e de carreiras para os profissionais e as pressões advindas das estratégias de barateamento de custos que podem se refletir na contratação de profissionais com menor titulação acadêmica e, portanto, com salários mais baixos, dentre outras.

Além disso, a complexidade que o tema formação envolve na atualidade é, dentre outros pontos, o desafio de pensar uma formação voltada para os aspectos da solidariedade e cidadania, ou seja, estabelecer uma oposição clara à "pseudoformação" dirigida para o mercado e para a competitividade e que traz a saúde como um bem de consumo. N esta medida, trata-se muito mais deestabelecer os pontos que seabrem para uma ampla discussão sobre formação, ensino e avaliação do ensino superior do que apresentar conclusões.

Um primeiro ponto a ser destacado refere-se aos conteúdos necessários para a formação em saúde e a inter-relação entre os mesmos, o que nos obriga a buscar um rompimento tanto com a lógica disciplinar, quanto com o processo de ensino-aprendizagem predominante. Transpor para a prática os princípios teóricos de qual quer proposta de mudança não é tar efa fácil. Além do mais, teremos que construir uma realidade bastante distinta daquela em que fomos formados. Traduzir em ações concretas a nossa compreensão dequeo conhecimento não éestanque, compartimentalizado e aprisionado na disciplina é perceber seu caráter dinâmico, as fronteiras e os entrelaçamentos queestabelece com outras áreas de conhecimento e novas formas de perceber a realidade a partir de múltiplos enfoques. Além disso, requer a análise crítica da hierarquização das áreas de conhecimento eas relações de poder que se estabelecem a partir do domínio de determinados saberes sobre outros.

Sobre a hierarquia do conhecimento e as relações de poder entre diferentes atores sociais envolvidos nos processos de saúde-adoecimento, vale pensar também o quanto tais questões influen ciam a dinâmica do ensino-apren dizagem. Sabemos que as relações de poder que se dão entre mestres e alunos são reproduzidas também entre a comunidade acadêmica e a população, na medida em que estudantes, professorese instituições de ensino lidam com as comunidades nas quais buscam se inserir para os estágios e demais trabal hos em campo, partindo do prin- cípio de que o conhecimento legitimo é o saber científico que se coloca em relação de superioridade a outras formas de conhecimento não acadêmicos. Frequentemente, ouvimos os protestos de indivíduos e comunidades que foram "alvo" do interesse de atividades acadêmicas e que depois ficaram no esquecimento ou sem uma resposta concreta aos problemas de seu cotidiano. Considerar sujeitos e coletividades como objetos de pesquisa edeintervenção éuma situação delicada e por que não dizer equivocada, parte do mito da neutralidadecientífica e podeconduzir a uma concepção utilitarista do homem. Mudar essa realidade é compreender o processo ensinoaprendizagem em sua dimensão política e ética, compreender as expectativas e compromissos sociais que as áreas de conhecimento estabelecem com a sociedade e pensar que a formação é não só aquisição de conteúdos, mas também construção de conhecimentos, desenvolvimento de indivíduos e coletividades que ensinam e aprendem conjuntamente, busca de autonomia e emancipação e responsabilidade social.

Em segundo lugar, mas inseparável da discussão da inter-relação de conteúdos, é a implementação das mudanças no processo de formação dos profissionais de saúde. Romper model os já estruturados exige um esforço para que se estabeleça um diálogo constante entre as novas propostas de formação que se apresentam e aquelas propostas que a antecederam. Somente a partir desta possibilidade de interlocução torna-se possível perceber pontos de defasagem eprecariedades dos modelos de formação vigentes e as vantagens de se lançar na empreitada de construir novos modelos. Ingênuo pensar que qualquer tipo de mudança se estabelece simplesmente pela ilusão de que a novidade é em si boa ou ruim. A maneira como se constroi ereconstroi a novidadeéquevai permitir que essa avaliação seja feita no futuro.

$\mathrm{N}$ ão podemos desconsiderar quevivemosum momento da história da humanidade no qual a velocidade das mudanças é tão grande que todos padecemos das dificuldades com o tempo. Torna-se bastante comum no nosso dia a dia ficarmos tomados pelas questões da perda de tempo, da falta de tempo, da associação entre tempo e dinheiro e do tempo que está passando muito rápido para todos. Dispensável dizer o quanto temos medo de perder tempo com propostas de mudança e 0 quanto essas sensações afetam a vida das pessoas. No entanto, queremos dar ênfase para o quanto estas questões afetam tudo aquilo quena vida dos seres humanos requer tempo, ou seja, os acontecimentos ea sucessão desses 
acontecimentos construindo experiências econhecimentos e que fazem parte de um processo de formação do homem, pensado aqui de forma abrangente, como o que é evocado na Paideia ${ }^{26}$.

Importante destacar que a Paideia demonstra que o conceito de formação para os gregos era muito mais abrangente do que o que temos hoje em nossa sociedade, que geralmente toma o conceito de formação e escolarização como sinônimos. Assim, a formação do homem grego considerava os aspectos da civilização, cultura, tradição, literatura e educação, entre outros, vinculadose dando uma ideia de unidade conceitual, tratava-se de um processo de construção consciente, distinto do adestramento em função de fins exteriores. $\mathrm{Na}$ concepção grega, a educação aparece não como uma propriedade individual, mas pertencente, por essência, à comunidade, não seconstituindo como um conjunto de técnicas e organizações privadas orientadas para a formação de uma individualidade perfeita eindependente.

Considerando que os diferentes aspectos do desenvolvimento humano requerem tempo e condições concretas para que possam ser considerados bem-sucedidos, necessariamente os processos de formação universitária, compreendidos num escopo abrangente da formação do homem, não acontecerão de forma instantânea e exigirão de nós um conhecimento mais profundo acerca do quanto estamos envolvido em aspectos de pseudoformação e o quanto um caminho para a formação exigirá de nós. 


\section{Referências}

1. Brasil. Decreto $n^{\circ}$ 6.096, de 24 de abril de 2007 . Institui o Programa de Apoio a Planos de Reestruturação e Expansão das Universidades Federais REUNI. Diário O ficial da União 2007; 24 abr.

2. Brasil. Constituição. Constituição da República Fede ral do Brasil. Brasília: Senado Federal; 1988.

3. Carneiro M A. LDB fácil: leitura crítico - compreensiva artigo a artigo. 11ª ed. Petrópolis: Vozes, 2004.

4. Calderon Al. Universidades mercantis: a institucionalização do mercado universitário em questão. Sao Paulo Perspec. 2000; 14(1): 61-72.

5. Sobral FAF. Educação para a competitividade ou para a cidadania social? Sao Paulo Perspec. 2000; 14(1): 3-11.

6. Martins $C B$. $O$ ensino superior brasileiro nos anos 90. Sao Paulo Perspec. 2000; 14(1): 41-60.

7. Brasil. M inistério da Educação e Cultura/Inep. Censo da Educação superior. [site da Internet] [acessado 2007 jun 20]. Disponível em: http://lpp-uerj.net/ olped/documentos/ppcor/0314.pdf

8. Ribeiro D. Avertencia. In: Ribeiro D. La Universidad nueva: un proyecto. Buenos Aires: Editorial Ciencia Nueva SRL; 1973.

9. Casanova PG. Universidad y Régimen In: Ribeiro D. La Universidad nueva: un proyecto. Buenos Aires: Editorial Ciencia Nueva SRL; 1973.

10. Santos BS. Um discurso sobre as Ciências. São Paulo: Cortez; 2003.

11. Domingues I, organizador. Conhecimento e transdisciplinaridade. Belo Horizonte: IEAT - UFM G; 2001.

12. Horkheimer $M$, Adorno TW. A indústria cultural: 0 esclarecimento como mistificação das massas. In: Horkheimer M, Adorno TW. Dialética do esclarecimento. Rio de Janeiro: Jorge Zahar; 1985.

13. Adorno TW. Teoria de la seudocultura. In: Horkheimer M, Adorno TW. Sociologia. Madrid: Taurus Ediciones; 1971.

14. Brasil. M inistério da Saúde. Secretaria de Gestão do Trabalho e da Educação na Saúde. Aprender SU S: o SUS e os cursos de graduação da área da saúde. Brasília: M inistério da Saúde; 2004.

15. World Health Organization. Constitution of the World Health Organization. Basic Documents. [site da Internet] [acessado $2007 \mathrm{abr}$ 12]. Disponível em: who.int/governance/eb/who_constitucion_en.pdf

16. Segre M, Ferraz FC. O conceito de saúde. Rev. Saude Publica 1997; 31(5): 538-542.
17. Brasil. M inistério da Saúde. Secretaria de Gestão do Trabalho e da Educação na Saúde. Curso de formação de facilitadores de Educação Permanente em Saúde. Rio de Janeiro: Fiocruz; 2005.

18. M inayo MCS. Saúde e doença como expressão cultural. In: Amâncio Filho A, M oreira M CGB, organizadores. Saúde, trabalho e formação profissional. Rio de Janeiro: Fiocruz; 1997.

19. M inayo M CS. Saúde-doença: uma concepção popular da etiologia. Cad Saude Publica 1988; 4(4):363381.

20. Arouca ASS. O Dilema preventivista: contribuição para a compreensão e crítica da medicina preventiva. Campinas: EPUC-Fiocruz; 2005.

21. Tambellini AMT. Questões introdutórias, razões, significados e afetos - expressões do "Dilema Preventivista" então e agora. In: Arouca ASS. 0 dilema preventivista: contribuição para a compreensão e crítica da medicina preventiva. Campinas: EPUC-Fiocruz; 2005.

22. Carvalho SR. Saúde coletiva e promoção da saúde: sujeito e mudança. São Paulo: Hucitec; 2005.

23. Nunes ED. M edicina social: aspectos históricos e teóricos. São Paulo: Global; 1983.

24. Brasil. M inistério da Saúde. Organização Pan-Americana da Saúde. Organização M undial de Saúde. Política de recursos humanos em saúde: seminário internacional. [site da Internet] [acessado 2005 jan 15]. Disponível em: http://whqlibdoc.who.int/publications/ 2002/8587943278_por.pdf

25. Brasil. Lei $n=8.080$ de 19 de setembro de 1990. Dispõe sobre as condições para a promoção, proteção e recuperação da saúde, organização e o funcionamento dos serviços correspondentes e dá outras providências. Diário Oficial da União 1990; 19 set.

26. Jaeger W. Introdução. In: Jaeger W. Paideia: a formação do homem grego. 4a ed. São Paulo: Martins Fontes; 2003.

Artigo apresentado em 25/06//2007

Aprovado em 10/10/2007

Versão final apresentada em 06/03/2008 